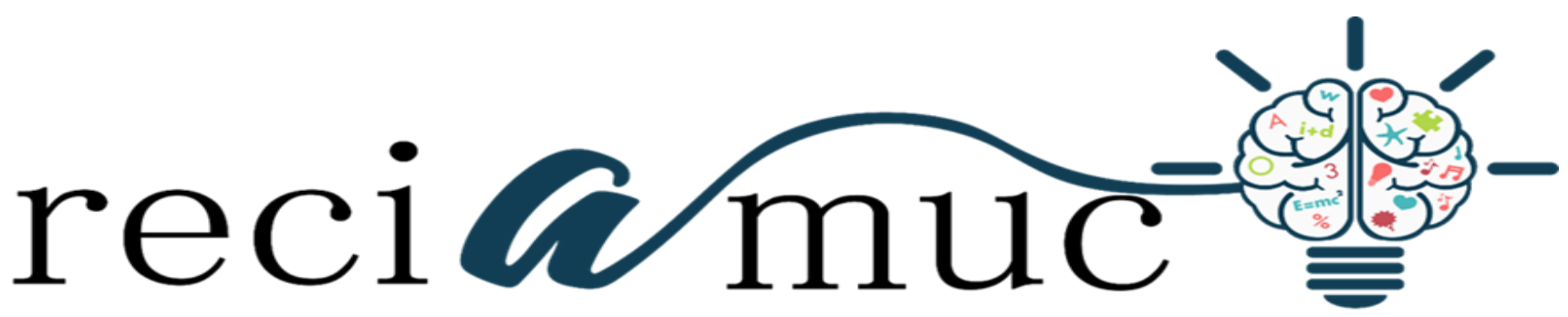

Revista cientifica de investigación actualización del mundo de las ciencias

Jorge Emilio Morante Arias ${ }^{\text {a }}$; Kempis Ismael Guerrero Franco ${ }^{\text {b; }}$ Denisse Pilar

Peñaherrera Salazar ${ }^{\text {c; }}$ Andrea Estefanía Zurita Beltrán ${ }^{\mathrm{d}}$

Conjuntivitis: revisión sistemática de diagnóstico y tratamiento

Conjunctivitis: systematic review of diagnosis and treatment

Revista Científica de Investigación actualización del mundo de las Ciencias. Vol. 3 núm., 1, enero, ISSN: 2588-0748, 2018, pp. 618-634

DOI: $10.26820 /$ reciamuc/3.(1).enero.2019.618-634

URL: $\underline{\text { http://reciamuc.com/index.php/RECIAMUC/article/view/250 }}$

Código UNESCO: 3205 Medicina Interna

Tipo de Investigación: Artículo de Revisión

Editorial Saberes del Conocimiento

Recibido: 10/12/2018

Aceptado: 20/01/2019

Publicado: 30/01/2019

Correspondencia: emiliox2102@ hotmail.com

a. Médico; Guayaquil, Ecuador; emiliox2102@ hotmail.com

b. Médico; Guayaquil, Ecuador; kempisismael88@ hotmail.com

c. Médico; Guayaquil, Ecuador; denisse89_@hotmail.com

d. Médico; Guayaquil, Ecuador; andrea.zurita89@hotmail.com 


\section{Conjuntivitis: revisión sistemática de diagnóstico y tratamiento}

Vol. 3, núm. 1., (2019)

Jorge Emilio Morante Arias; Kempis Ismael Guerrero Franco; Denisse Pilar Peñaherrera Salazar;

Andrea Estefanía Zurita Beltrán

\section{RESUMEN}

El objetivo de este trabajo es examinar el diagnóstico, manejo y tratamiento de la conjuntivitis, incluyendo diversos antibióticos y alternativas a la utilización de antibióticos en la conjuntivitis infecciosa y el uso de los antihistamínicos y los estabilizadores de los mastocitos en la conjuntivitis alérgica. La conjuntivitis viral es la causa global más común de conjuntivitis infecciosa y por lo general no requiere tratamiento; los signos y síntomas de presentación son variables. La conjuntivitis bacteriana es la segunda causa más común de conjuntivitis infecciosa, con la mayoría de los casos no complicados resolver en 1 a 2 semanas. Importando y la adhesión de los párpados al despertarse, la falta de picor, y la ausencia de una historia de la conjuntivitis son los factores más fuertes asociadas con la conjuntivitis bacteriana. Los antibióticos tópicos disminuyen la duración de la conjuntivitis bacteriana y permitir a principios de regreso a la escuela o el trabajo. Conjuntivitis secundaria a enfermedades de transmisión sexual como la clamidia y la gonorrea requiere tratamiento sistémico además de la terapia antibiótica tópica. La conjuntivitis alérgica se encuentra en hasta el $40 \%$ de la población, pero sólo una pequeña proporción de estos individuos buscan ayuda médica. La mayoría de los casos de conjuntivitis bacteriana sonauto-limitante y no se necesita tratamiento en casos sin complicaciones. Sin embargo, la conjuntivitis causada por gonorrea o clamidia y conjuntivitis en usuarios de lentes de contacto debe ser tratada con antibióticos. El tratamiento de la conjuntivitis viral es de apoyo. El tratamiento con antihistamínicos y estabilizadores de mastocitos alivia los síntomas de la conjuntivitis alérgica.

Palabras Claves: Conjuntivitis Bacteriana; Diagnóstico; Tratamiento; Infección. 


\title{
Conjuntivitis: revisión sistemática de diagnóstico y tratamiento
}

Vol. 3, núm. 1., (2019)

Jorge Emilio Morante Arias; Kempis Ismael Guerrero Franco; Denisse Pilar Peñaherrera Salazar; Andrea Estefanía Zurita Beltrán

\begin{abstract}
The objective of this work is to examine the diagnosis, management and treatment of conjunctivitis, including various antibiotics and alternatives to the use of antibiotics in infectious conjunctivitis and the use of antihistamines and mast cell stabilizers in allergic conjunctivitis. Viral conjunctivitis is the most common global cause of infectious conjunctivitis and usually does not require treatment; the signs and symptoms of presentation are variable. Bacterial conjunctivitis is the second most common cause of infectious conjunctivitis, with most uncomplicated cases resolved in 1 to 2 weeks. Importing and adhering the eyelids upon awakening, lack of itching, and the absence of a history of conjunctivitis are the strongest factors associated with bacterial conjunctivitis. Topical antibiotics decrease the duration of bacterial conjunctivitis and allow early return to school or work. Conjunctivitis secondary to sexually transmitted diseases such as chlamydia and gonorrhea requires systemic treatment in addition to topical antibiotic therapy. Allergic conjunctivitis is found in up to $40 \%$ of the population, but only a small proportion of these individuals seek medical help. Most cases of bacterial conjunctivitis are self-limiting and treatment is not needed in uncomplicated cases. However, conjunctivitis caused by gonorrhea or chlamydia and conjunctivitis in contact lens wearers should be treated with antibiotics. The treatment of viral conjunctivitis is supportive. Treatment with antihistamines and mast cell stabilizers relieves the symptoms of allergic conjunctivitis.
\end{abstract}

Key Words: Bacterial Conjunctivitis; Diagnosis; Treatment; Infection. 


\section{Conjuntivitis: revisión sistemática de diagnóstico y tratamiento}

Vol. 3, núm. 1., (2019)

Jorge Emilio Morante Arias; Kempis Ismael Guerrero Franco; Denisse Pilar Peñaherrera Salazar;

Andrea Estefanía Zurita Beltrán

\section{Introducción.}

La conjuntiva es una membrana delgada, translúcida que recubre la parte anterior de la esclerótica y en el interior de los párpados. Tiene 2 partes, bulbar y palpebral. La porción bulbar comienza en el borde de la córnea y cubre la parte visible de la esclerótica; las líneas porción palpebral el interior de los párpados (figura 1). La inflamación o infección de la conjuntiva se conoce como conjuntivitis y se caracteriza por dilatación de los vasos de la conjuntiva, lo que resulta en hiperemia y edema de la conjuntiva, típicamente con descarga asociada. (Leibowitz, 2000)

La conjuntivitis afecta a muchas personas e impone cargas económicas y sociales. Se estima que la conjuntivitis aguda afecta a6 millones de personas anualmente solo en los Estados Unidos (Udeh, Schneider, \& Ohsfeldt, 2008) El costo del tratamiento de la conjuntivitis bacteria solo se estimó en \$ 377 millones a \$ 857 millones por año. Muchos departamentos de salud estatales de Estados Unidos, independientemente de la causa subyacente de la conjuntivitis, requieren que los estudiantes puedan ser tratados con colirios, antibióticos y tópicos antes de regresar a la escuela.

La mayoría de los pacientes con conjuntivitis son tratados inicialmente por los médicos de atención primaria en lugar de profesionales de la visión. Aproximadamente el 1\% de todas las consultas de atención primaria están relacionadas a la conjuntivitis. Aproximadamente el $70 \%$ de todos los pacientes con conjuntivitis aguda se presentan en atención primaria y atención de emergencias (Kaufman, 2011) 


\section{Conjuntivitis: revisión sistemática de diagnóstico y tratamiento}

Vol. 3, núm. 1., (2019)

Jorge Emilio Morante Arias; Kempis Ismael Guerrero Franco; Denisse Pilar Peñaherrera Salazar; Andrea Estefanía Zurita Beltrán

La prevalencia de la conjuntivitis varía en función de la causa bajo-mentira, que puede estar influenciado por la edad del paciente, así como la estación del año. La conjuntivitis viral es la causa más común de conjuntivitis infecciosa sobre todo en la población adulta y es más prevalente en verano. La conjuntivitis bacteriana es la segunda causa más común y es responsable de la mayoría $(50 \%-75 \%)$ de los casos en niños; se observa con más frecuencia de diciembre a abril (Høvding, 2008)

\section{Figura 1. Anatomía de la conjuntivitis}

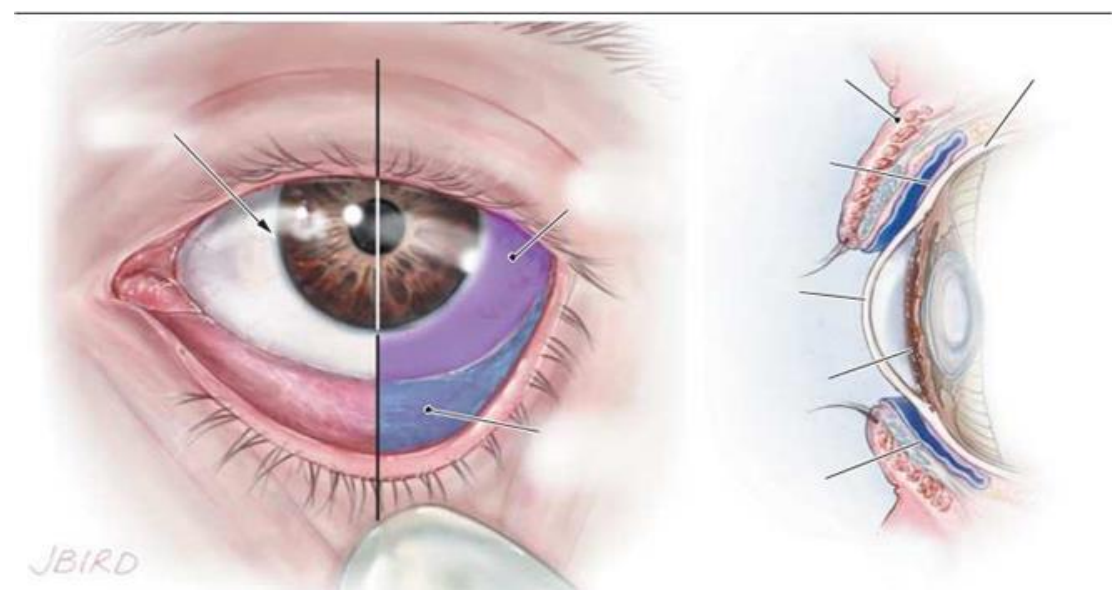

La conjuntivitis se puede dividir en causas infecciosas y no infecciosas. Los virus y las bacterias son las causas infecciosas más comunes. La conjuntivitis no infecciosa incluye conjuntivitis alérgica, tóxica, y cicatricial, así como la inflamación secundaria a enfermedades inmunes y procesos neoplásicos. La enfermedad también puede ser clasificada en aguda, hiperagudo y crónica de acuerdo con el modo de aparición y la gravedad de la respuesta clínica. Además, puede ser primaria o secundaria a enfermedades sistémicas tales como la gonorrea, clamidia, enfermedad de injerto contra huésped, y síndrome de Reiter, en las que se justifica caso de tratamiento sistémico. 


\section{Conjuntivitis: revisión sistemática de diagnóstico y tratamiento}

Vol. 3, núm. 1., (2019)

Jorge Emilio Morante Arias; Kempis Ismael Guerrero Franco; Denisse Pilar Peñaherrera Salazar; Andrea Estefanía Zurita Beltrán

Es importante diferenciar la conjuntivitis de otras enfermedades oculares que amenazan la vista que tienen presentación clínica similar y para tomar decisiones apropiadas sobre más pruebas, o tratamientos.

\section{Metodología.}

Para el desarrollo de este proceso investigativo, se plantea como metodología la encaminada hacia una orientación científica particular que se encuentra determinada por la necesidad de indagar en forma precisa y coherente una situación, en tal sentido (Davila, 2015) define la metodología "como aquellos pasos previos que son seleccionados por el investigador para lograr resultados favorables que le ayuden a plantear nuevas ideas”. (p.66)

Lo citado por el autor, lleva a entender que el desarrollo de la acción investigativa busca simplemente coordinar acciones enmarcadas en una revisión bibliográfica con el fin de complementar ideas previas relacionadas a la conjuntivitis a través de una revisión de literatura, para así finalmente elaborar un cuerpo de consideraciones generales que ayuden a ampliar el interés propuesto.

Tipo de Investigación

Dentro de toda práctica investigativa, se precisan acciones de carácter metodológico mediante las cuales, se logra conocer y proyectar los eventos posibles que la determinan, así como las características que hacen del acto científico un proceso interactivo ajustado a una realidad posible de ser interpretada. En este sentido, se puede decir, que la presente investigación corresponde al tipo documental, definido por Castro (2016), "se ocupa del estudio de problemas 


\section{Conjuntivitis: revisión sistemática de diagnóstico y tratamiento}

Vol. 3, núm. 1., (2019)

Jorge Emilio Morante Arias; Kempis Ismael Guerrero Franco; Denisse Pilar Peñaherrera Salazar; Andrea Estefanía Zurita Beltrán

planteados a nivel teórico, la información requerida para abordarlos se encuentra básicamente en materiales impresos, audiovisuales y /o electrónicos”. (p.41).

En consideración a esta definición, la orientación metodológica permitió la oportunidad de cumplir con una serie de actividades inherentes a la revisión y lectura de diversos documentos donde se encontraron ideas explicitas relacionadas con los tópicos encargados de identificar a cada característica insertada en el estudio. Por lo tanto, se realizaron continuas interpretaciones con el claro propósito de revisar aquellas apreciaciones o investigaciones propuestas por diferentes investigadores relacionadas con el tema de interés, para luego dar la respectiva argumentación a los planteamientos, en función a las necesidades encontradas en la indagación.

\section{Fuentes Documentales}

El análisis correspondiente a las características que predomina en el tema seleccionado, llevan a incluir diferentes fuentes documentales encargadas de darle el respectivo apoyo y en ese sentido cumplir con la valoración de los hechos a fin de generar nuevos criterios que sirven de referencia a otros procesos investigativos. Para (CASTRO, 2016) las fuentes documentales incorporadas en la investigación documental o bibliográfica, "representa la suma de materiales sistemáticos que son revisados en forma rigurosa y profunda para llegar a un análisis del fenómeno". (p.41). Por lo tanto, se procedió a cumplir con la realización de una lectura previa determinada para encontrar aquellos aspectos estrechamente vinculados con el tema, con el fin de explicar mediante un desarrollo las respectivas apreciaciones generales de importancia. 


\section{Conjuntivitis: revisión sistemática de diagnóstico y tratamiento}

Vol. 3, núm. 1., (2019)

Jorge Emilio Morante Arias; Kempis Ismael Guerrero Franco; Denisse Pilar Peñaherrera Salazar;

Andrea Estefanía Zurita Beltrán

\section{Técnicas para la Recolección de la Información}

La conducción de la investigación para ser realizada en función a las particularidades que determinan a los estudios documentales, tiene como fin el desarrollo de un conjunto de acciones encargadas de llevar a la selección de técnicas estrechamente vinculadas con las características del estudio. En tal sentido, (Bolívar, 2015), refiere, que es "una técnica particular para aportar ayuda a los procedimientos de selección de las ideas primarias y secundarias”. (p. 71).

Por ello, se procedió a la utilización del subrayado, resúmenes, fichaje, como parte básica para la revisión y selección de los documentos que presentan el contenido teórico. Es decir, que mediante la aplicación de estas técnicas se pudo llegar a recoger informaciones en cuanto a la revisión bibliográfica de los diversos elementos encargados de orientar el proceso de investigación. Tal como lo expresa, (Bolívar, 2015) "las técnicas documentales proporcionan las herramientas esenciales y determinantes para responder a los objetivos formulados y llegar a resultados efectivos" (p. 58). Es decir, para responder con eficiencia a las necesidades investigativas, se introdujeron como técnica de recolección el método inductivo, que hizo posible llevar a cabo una valoración de los hechos de forma particular para llegar a la explicación desde una visión general.

Asimismo, se emplearon las técnicas de análisis de información para la realización de la investigación que fue ejecutada bajo la dinámica de aplicar diversos elementos encargados de determinar el camino a recorrer por el estudio, según, (Bolívar, 2015) las técnicas de procesamiento de datos en los estudios documentales "son las encargadas de ofrecer al investigador la visión o pasos que debe cumplir durante su ejercicio, cada una de ellas debe estar 


\section{Conjuntivitis: revisión sistemática de diagnóstico y tratamiento}

Vol. 3, núm. 1., (2019)

Jorge Emilio Morante Arias; Kempis Ismael Guerrero Franco; Denisse Pilar Peñaherrera Salazar; Andrea Estefanía Zurita Beltrán

en correspondencia con el nivel a emplear" (p. 123). Esto indica, que para llevar a cabo el procesamiento de los datos obtenidos una vez aplicado las técnicas seleccionadas, tales como: fichas de resumen, textual, registros descriptivos entre otros, los mismos se deben ajustar al nivel que ha sido seleccionado.

\section{Resultados.}

La exploración ocular centrado y la historia son cruciales para la toma de decisiones sobre el tratamiento y la gestión de la condición de cualquier ojo, incluyendo conjuntivitis. El tipo de descarga de los ojos y síntomas oculares se puede utilizar para determinar la causa de la conjuntivitis. Por ejemplo, una purulenta o mucopurulenta descarga es a menudo debido a la conjuntivitis bacteriana (Figura 2A y la Figura 2B), mientras que un flujo acuoso es más característico de la conjuntivitis viral (Figura 2C); la picazón también está asociada con la conjuntivitis alérgica.

Sin embargo, la presentación clínica suele ser inespecífica. Confiar en el tipo de descarga y síntomas del paciente no siempre conduce a un diagnóstico preciso. Por otra parte, evidencia científica y correlación de signos y síntomas de la conjuntivitis con la causa subyacente es a menudo insuficiente. Por ejemplo, en un estudio de pacientes con conjuntivitis bacteriana con cultivo positivo, el $58 \%$ tenía picor, $65 \%$ tenían ardor, y $35 \%$ tenían ojo seroso y nada de descarga en absoluto, que ilustra la no especificidad de los signos y síntomas de este di facilidad (Rietveld, ter Riet, Bindels, Sloos, \& van Weert, 2004). En 2003, una gran meta-análisis no encontró ningún prisionero clínico en correlación de los signos y síntomas de la conjuntivitis con la causa anti-derlying; más tarde, los mismos autores realizaron un estudio prospectivo y 


\section{Conjuntivitis: revisión sistemática de diagnóstico y tratamiento}

Vol. 3, núm. 1., (2019)

Jorge Emilio Morante Arias; Kempis Ismael Guerrero Franco; Denisse Pilar Peñaherrera Salazar; Andrea Estefanía Zurita Beltrán

encontraron que una combinación de 3-signos bilaterales de los párpados, la falta de picor, y sin antecedentes de conjuntivitis predijo fuertemente la conjuntivitis bacteriana. Teniendo ambos ojos adheridos en la mañana fue un predictor más fuerte para el resultado cultivo bacteriano positivo, y, o bien picazón o un anterior episodio de la conjuntivitis hizo un cultivo bacteriano positivo resultado menos probable. Además, el tipo de descarga (purulenta, moco o acuosos) síntomas u otros no eran específicos para cualquier clase particular de conjuntivitis. (Tarabishy \& Jeng, 2008)

Aunque en el contexto de atención primaria de un examen ocular es a menudo limitada debido a la falta de una lámpara de hendidura, la información útil puede obtenerse con una simple linterna de bolsillo. El examen de los ojos debe enfocarse en la evaluación de la agudeza visual, el tipo de descarga, opacidad corneal, forma y tamaño de la pupila, hinchazón de los párpados, y presencia de prótesis.

La conjuntivitis infecciosa

La conjuntivitis viral

Epidemiología, Causa y Presentación

Los virus causan hasta el $80 \%$ de todos los casos de conjuntivitis aguda. La tasa de precisión clínica en el diagnóstico de la conjuntivitis viral es menor que $50 \%$ en comparación con la confirmación de laboratorio. Muchos de los casos se diagnostican erróneamente como la conjuntivitis bacteriana. 


\section{Conjuntivitis: revisión sistemática de diagnóstico y tratamiento}

Vol. 3, núm. 1., (2019)

Jorge Emilio Morante Arias; Kempis Ismael Guerrero Franco; Denisse Pilar Peñaherrera Salazar; Andrea Estefanía Zurita Beltrán

Entre $65 \%$ y $90 \%$ de los casos de conjuntivitis viral son causadas por adenovirus, y que producen 2 de los casos clínicos comunes asociados con la conjuntivitis viral, fiebre faringoconjuntival y queratoconjuntivitis epidémica (Yannof \& Duker, 2004). La fiebre faringoconjuntival se caracteriza por la aparición brusca de fiebre alta, faringitis y conjuntivitis bilateral, y por ganglio linfático ampliamente periauricular, mientras que la queratoconjuntivitis epidémica es más grave y se presenta con descarga acuosa, hiperemia, quemosis, y linfadenopatía ipsilateral. Lalinfadenopatía se observa en hasta un 50\%de los casos de conjuntivitis viral y es más prevalente en la conjuntivitis viral en comparación con la conjuntivitis bacteriana.

\section{Prevención y Tratamiento}

La conjuntivitis viral secundaria o adenovirus es muy contagiosa, y el riesgo de transmisión ha sido estimada en $10 \%$ a $50 \%$. El virus se propaga a través del contacto directo a través de los dedos contaminados, instrumentos médicos, agua de la piscina, o artículos de uso personal; En un estudio, el $46 \%$ de las personas infectadas tenían cultivos positivos cultivadas a partir de hisopos de sus manos (Azar, Dhaliwal, \& Bower, 1996). Debido a las altas tasas de transmisión, el lavado de manos, desinfección estricta de instrumento, y el aislamiento de los pacientes en infectados del resto de la clínica se ha defendido. La incubación y comunicabilidad se estima en 5 a 12 días y de 10 a 14 días, respectivamente.

Aunque no existe un tratamiento eficaz, lágrimas artificiales, tópicos antihistamínicos, o compresas frías pueden ser útiles en el alivio de algunos de los síntomas. Medicamentos antivirales no son útiles y antibióticos tópicos no se indican ya que estos no protegen contra las 


\section{Conjuntivitis: revisión sistemática de diagnóstico y tratamiento}

Vol. 3, núm. 1., (2019)

Jorge Emilio Morante Arias; Kempis Ismael Guerrero Franco; Denisse Pilar Peñaherrera Salazar; Andrea Estefanía Zurita Beltrán

infecciones secundarias, y su uso puede complicar la presentación clínica, causando alergia y toxicidad, lo que lleva a retraso en el diagnóstico de otras enfermedades oculares posibles. El uso de gotas de antibiótico puede aumentar el riesgo de propagación de la infección al otro ojo de goteros contaminados. El Aumento de la resistencia es también motivo de preocupación con el uso frecuente de antibióticos. Pacientes deben ser remitidos a un oftalmólogo si los síntomas no se resuelven después de 7 a 10 días, debido al riesgo de complicaciones.

\section{La conjuntivitis de herpes}

El virus herpes simple comprende del $1,3 \%$ al $4,8 \%$ de todos los casos de conjuntivitis aguda (Woodland, Darougar, \& Thaker, 1992). La conjuntivitis causada por el virus suele ser uni-lateral. La descarga es delgada y acuosa, y las lesiones de los párpados vesicular adjuntos puede estar presente. Antivirales tópicos y orales son recomendados para acortar el curso de la enfermedad. Los corticosteroides tópicos deben ser evitados, ya que potencian el virus y pueden causar daño.

El virus del herpes zoster, responsable de la culebrilla, puede afectar el tejido ocular, sobre todo si la primera y segunda ramas del nervio trigeminal están involucrados. Párpados $(45,8 \%)$ son el sitio más común de la implicación ocular, seguida de la conjuntiva $(41,1 \%)$, la complicación corneal y la uveítis pueden estar presentes en $38,2 \%$ y $19,1 \%$ de los casos, respectivamente. Los pacientes con sospecha de párpados o el ojo envolvente o los que presentan signo de Hutchinson (vesículas en la punta de la nariz, que tiene una alta correlación con la córnea) debe ser sometida a una evaluación oftalmológica completa. El tratamiento generalmente consiste en una combinación de antivirales orales y esteroides topi-cal. 


\section{Conjuntivitis: revisión sistemática de diagnóstico y tratamiento}

Vol. 3, núm. 1., (2019)

Jorge Emilio Morante Arias; Kempis Ismael Guerrero Franco; Denisse Pilar Peñaherrera Salazar; Andrea Estefanía Zurita Beltrán

\section{La conjuntivitis bacteriana}

\section{Epidemiología, Causa y Presentación}

La incidencia de conjuntivitis bacteriana se estimó en 135 en 10000 en un estudio (Smith \& Waycaster, 2009). La conjuntivitis bacteriana se puede contraer directamente de individuos infectados o puede ser resultado de una anormal proliferación de la flora conjuntival en nativos. Los dedos contaminados, difusión oculogenital y fómites contaminadosson vías de transmisión. Además, ciertas condiciones tales como la producción de lágrima, la interrupción de la barrera epitelial natural, anormalidad de estructuras anexas, trauma, y el estado de inmunosupresión prensado predisponen a la conjuntivitis bacteriana. Los patógenos más comunes para la conjuntivitis bacteriana en adultos son especies staphy-lococcal, seguido de Streptococcuspneumoniae y influenzae Hae-mophilus. En los niños, la enfermedad es causada a menudo por H influenzae, S pneumoniae y Moraxellacatarrhalis.El curso de la enfermedad por lo general dura de 7 a 10 días.

La conjuntivitis bacteriana hiperaguda se presenta con una severa secreción purulenta abundante y disminución de la visión. Ahí menudo acompaña la hinchazón de los párpados, el dolor ocular al palpar y adenopatía preauricular. A menudo es causada por Neisseriagonorrhoeaey conlleva un alto riesgo de afectación corneal y su posterior perforación corneal. El tratamiento de la conjuntivitis hiperagudasecundaria a $\mathrm{N}$ gonorrea consiste en tratamientointramuscular. La ceftriaxona y la infección por clamidia concurrentes deben manejarseen consecuencia. La conjuntivitis bacteriana crónica se usa para describir cualquier conjuntivitis con una duración de más de 4 semanas, con Staphylococcusaureus, 


\section{Conjuntivitis: revisión sistemática de diagnóstico y tratamiento}

Vol. 3, núm. 1., (2019)

Jorge Emilio Morante Arias; Kempis Ismael Guerrero Franco; Denisse Pilar Peñaherrera Salazar; Andrea Estefanía Zurita Beltrán

Moraxellalacunata, y las bacterias intrínsecas son las más comunes en este escenario; se debe buscar consulta oftalmológica para administración.

Los signos y síntomas incluyen ojo rojo, purulento o mucopurulento, descarga y quemosis. El período de incubacióny la comunicabilidad se estima en 1 a 7 días y 2 a 7 díasrespectivamente. La importancia bilateral de los párpados y adherencia de los párpados, la falta de picazón y la no historia de la conjuntivitis son fuertes predictores positivos de conjuntivitis bacteriana. Secreción purulenta grave siempre se debe cultivar y conjuntivitis gonocócica debe considerarse.

Uso de antibióticos en la conjuntivitis bacteriana

Al menos el $60 \%$ de los casos de bacterias agudas sospechosas o probadas en cultivo a las conjuntivitis son autolimitadas dentro de 1 a 2 semanas de presentación. Aunque los antibióticos tópicos reducen la duración dela enfermedad, no se han observado diferencias en los resultados entre el tratamiento y el lugar

Todo el antibiótico de amplio espectro en general para ser eficaz en el tratamiento de la conjuntivitis bacteriana. Ahí no hay diferencias significativas en el logro de la cura clínica entre cualquiera de los antibióticos tópicos de amplio espectro. Factores que influyen en las opciones de antibióticoson disponibilidad local, alergias de los pacientes, patrones de resistencia,y el costo.

Los esteroides tópicos deben evitarse debido al riesgo de prolongar potencialmente el curso de la enfermedad y potenciarlo. 


\section{Conjuntivitis: revisión sistemática de diagnóstico y tratamiento}

Vol. 3, núm. 1., (2019)

Jorge Emilio Morante Arias; Kempis Ismael Guerrero Franco; Denisse Pilar Peñaherrera Salazar; Andrea Estefanía Zurita Beltrán

Para el manejo de la conjuntivitis bacteriana en conclusión, los beneficios del tratamiento con antibióticos incluyen una recuperación más rápida, disminución de la transmisibilidad y regreso temprano a la escuela. Simultáneamente, los efectos adversos están ausentes si no se usan antibióticos en casos no complicados de conjuntivitis bacteriana. Por lo tanto, el tratamiento, la política de esperar y ver y el tratamiento inmediato aparecen ser abordajes razonables en casos de conjuntivitis no complicada.

El tratamiento antibiótico debe ser considerado en casos de purulentao conjuntivitis mucopurulenta y para pacientes que tienen incomodidad distintiva, quienes usan lentes de contacto, que están inmunocomprometidos y que tienen sospecha de clamidia y gonococo.

\section{La conjuntivitis no infecciosa}

\section{Conjuntivitis alérgica}

Prevalencia y causa

La conjuntivitis alérgica es la respuesta inflamatoria de la conjuntiva a los alergenos tales como el polen, caspa de animales, y otros antígenos-ambientales; sólo el 10\% de los individuos con conjuntivitis alérgica busca atención médica, y la entidad es infradiagnosticada (Rosario \& Bielory, 2011). Enrojecimiento y la picazón son los síntomas más consistentes.

\section{Conclusiones.}

Aproximadamente el 1\% de todas las visitas de pacientes a un médico de atención primaria son la conjuntivitis relacionados, y el costo estimado de la conjuntivitis bacteriana es 


\section{Conjuntivitis: revisión sistemática de diagnóstico y tratamiento}

Vol. 3, núm. 1., (2019)

Jorge Emilio Morante Arias; Kempis Ismael Guerrero Franco; Denisse Pilar Peñaherrera Salazar; Andrea Estefanía Zurita Beltrán

solo \$ 377 millones a \$ 857 millones de dólares anuales. Basándose en los signos y síntomas a menudo conduce a un diagnóstico incorrecto. La conjuntivitis viral seguida de la conjuntivitis bacteriana es la causa más común para la conjuntivitis infecciosa. La conjuntivitis alergica afecta a casi el $40 \%$ de la población, pero sólo una pequeña proporción busca atención médica. La mayoría de los casos con-conjuntivitis viral se deben a adenovirus. No hay un papel para el uso de antibióticos tópicos en la conjuntivitis viral, y que debe evitarse debido a los efectos adversos del tratamiento. Usando una prueba rápida de antígenos para diagnosticar la conjuntivitis viral y evitar el uso inapropiado de antibióticos es una estrategia apropiada. Los patógenos bacterianos se precisan en sólo el $50 \%$ de los casos de sospecha de conjuntivitis, y al menos $60 \%$ de la conjuntivitis bacteriana (sospecha clínica o cultivo probado) es autolimitada sin tratamiento. Los cultivos son útiles en los casos que no responden a la terapia, los casos de conjuntivitis hiperaguda, y sospecha de conjuntivitis por clamidia. El tratamiento con antibióticos tópicos generalmente se recomienda para pacientes con lentes de contacto, aquellos con descarga mucopurulenta y dolor ocular, los casos sospechosos de clamidias y conjuntivitis gonocócica, y los pacientes con enfermedad preexistente de la superficie ocular. Las ventajas del uso antibiótica incluyen la resolución temprana de la enfermedad, pronto regreso al trabajo o la escuela y la posibilidad de complicaciones disminuye. La mayoría de los casos de conjuntivitis alérgica se deben a alergias estacionales. Los antihistamínicos, inhibidores de mastocitos, y esteroides tópicos (en casos seleccionados) están indicados para el tratamiento de la conjuntivitis alergica. Los esteroides deben utilizarse juiciosamente y sólo después de haber realizado un examen oftalmológico a fondo para descartar la infección o afectación de la córnea los cuales pueden empeorar con esteroides. 


\section{Conjuntivitis: revisión sistemática de diagnóstico y tratamiento}

Vol. 3, núm. 1., (2019)

Jorge Emilio Morante Arias; Kempis Ismael Guerrero Franco; Denisse Pilar Peñaherrera Salazar; Andrea Estefanía Zurita Beltrán

\section{Bibliografía.}

Azar, M., Dhaliwal, D., \& Bower, K. (1996). Possible consequences of shaking hands with your patients with epidemic keratoconjunctivitis. Am J Ophthalmol, 711-712.

Bolívar, J. (2015). Investigación Documental. México: Pax.

Castro, J. (2016). Técnicas Documentales. México: Limusa.

Davila, A. (2015). Concepto de terminos cientificos. Caracas: Oasis.

Høvding, G. (2008). Acute bacterial conjunctivitis. Acta Ophthalmol, 5-17.

Kaufman, H. (2011). Adenovirus advances: new diagnostic and therapeutic options. Curr Opin Ophthalmol, 290-293.

Leibowitz, H. (2000). El ojo rojo. N Engl J Med, 343(5), 345-351.

Rietveld, R., ter Riet, G., Bindels, P., Sloos, J., \& van Weert, H. (2004). Predicting bacterial cause in infectious conjunctivitis. BMJ, 206-210.

Rosario, N., \& Bielory, L. (2011). Epidemiology of allergic conjunctivitis. . Curr Opin Allergy Clin Immunol., 471-476.

Smith, A., \& Waycaster, C. (2009). Estimate of the direct and indirect annual cost of bacterial conjunctivitis in the United States. . BMC Ophthalmol., 9-13.

Tarabishy, A., \& Jeng, B. (2008). Bacterial conjunctivitis: a review for internists. Cleve Clin J Med, 507-512.

Udeh, B., Schneider, J., \& Ohsfeldt, R. (2008). Relación coste-efectividad de una prueba de punto de atención para la conjuntivitis por adenovirus. Am J Med Sci, 336(3), 254-264.

Woodland, R., Darougar, S., \& Thaker, U. (1992). Causes of conjunctivitis and keratoconjunctivitis in Karachi, Pakistan. Trans R Soc Trop Med Hyg., 317-320.

Yannof, J., \& Duker, J. (2004). Disorders of the conjunctiva and limbus. . Spain: Mosby. 